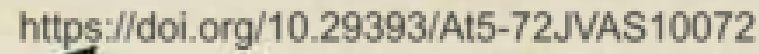 \\ Atenea
}

Revista publicada por la Universidad de Concepción COMISIÓN DIRECTORA:

Enrique Molina, Samuel Zenteno A., Luis D. Cruz Ocampo, Salvador Gálvez y Abraham Valenzuela C. (Secretario). EDITOR Y AGENTE GENERAL: CARLOS JORGE NASCIMENTO

\begin{tabular}{lll}
\hline \hline AÑO I & AGOSTO DE 1924 & NúM. 5 \\
\hline \hline
\end{tabular}

\section{Algo sobre Camoens}

(Lectura hecha en la velada conmemorativa del cuarto cenfenorio de su nacimienfo)

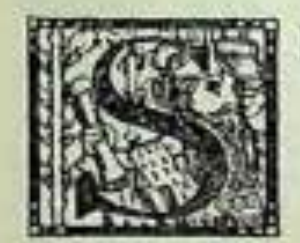

EÑOR Presidente, señoras, señores:

Al alborear el siglo diez y seis, dos tendencias bien definidas. y en cierta manera antagónicas, se diseñaban en la poesía portuguesa: la tendencia medioeval, preponderante en los siglos anteriores. y la tendencia clásica. caracterizada por la imilación de las obras de la antigüedad greco-latina.

Durante los siglos doce, trece y catorce, dió vida y explendor a la primera. la influencia, en la lírica portuguesa, de la poesia provenzal, y en la épica. la de las gestas del norte de Francia: al par que la segunda. latente, si se quiere. no fenecida. en aquel largo periodo, tuvo pocas ocasiones de manifestarse, y sólo vino a dar testimonio de su existencia en la segunda mitad del siglo quince. y mejor aún, en los primeros años del siglo diez y seis, en que se alzó omnipotente, amenazando concluir con su ya entonces desairada rival.

La poesia portuguesa, al finalizar la primera mitad del siglo diez y seis. estaba. pues. cercana a ver extinguirse toda una tradición poética. amasada en el largo espacio de tres centurias. con la substancia de su propia nacionalidad. La desintegración parecia fatal, y sólo el advenimiento de un hombre extraordinario. capaz de crear algo nuevo y peregrino, refundiendo elementos heterogéneos. podia oponerse a esta disolución. El genio de la raza reunió entonces todas sus energías y engendró a Luis de Camoens.

Nació este insigne poeta, honra elerna de la nación portuguesa. en Lisboa. el 10 de junio de 1524 . Su familia paterna era oriunda de Galicia, la patria 
de Macias, el trovador enamorado cuyas desgracias han dado la vuelta al mundo. Fueron sus padres, Simón Vaz Camoens. segundo nieto del trovador gallego Vasco Pires de Camoens, y doña Ana de Sá y Macedo. de los Gamas del Algarve. Cursó humanidades en la Universidad de Coimbra, bajo la inme. diata tutela de su tio don Benito de Camoens, que era canciller de ella. En 1542 frecuentó la corte de don Juan III a la que concurrían los más ilustres ingenios de su tiempo, y donde el talento era la única recomendación valedera para alcanzar empleos y honores. No los obtuvo Camoens. ¿Por qué? Sus biógrafos hablan de la envidia de las mediocridades: de la interpretación malévola que se dió a alguna obra suya: de su amor por doña Catalina de Alaíde. muy poco grato a la familia de esta joven. Camoens, más sincero, atribuyó sus desgracias a cyerros míos, amor y mala fortuna.

Obligado a salir de la Corte, Camoens, tras breves correrias, se embarca para Africa, donde permaneció dos años y perdió el ojo derecho, en una sorpresa de los moros. A su regreso a Lisboa, renacen sus esperanzas de alcanzar mejor fortuna, con la protección del principe don Juan. admirador fervoroso de los poetas de su época. Sin embargo, no la obtuvo esta vez tampoco. ¿Por qué? Sus biógrafos tornan a hablar de las conspiraciones de la envidia, y de la enemiga que su antiguo amor por doña Catalina de Ataíde. le había concitado en las familias de otras damas que tenían el mismo nombre. acaso por los equívocos a que esto se prestaba: pero refieren tambiēn que Camoens, en la procesión de Corpus, dió una cuchillada a Gonzalo Borges. cuñado de una de esas damas homónimas, y que por causa de esta agresión y desacato. fuć recluido en la prisión de Tronco. de donde no salió hasta el año siguiente. Sus forzados ocios de recluso, los empleó el poeta en una labor gloriosa: ahi compuso el primer canto de Os Lusiadas.

Obsesionado por el pensamiento de una epopeya nacional. apenas obtiene su liberlad se embarca para la India, y en la expedición contra el Chembé se bate heroicamente. Luego después, parte para la China, con un empleo civil en la colonia de Macao, y dos años más tarde es llamado a Goa, bajo apercibimiento de prisión, a causa de unos schismes de amigos. según dice uno de sus biógrafos. En Macao adelantó su poema hasta el canto séptimo. Llegado náufrago a Goa, sin haber logrado salvar ofros bienes que el inestimable del manuscrito de su epopeya, y preso ahi hasta que se justificara, recibió la nolicia de la muerte de doña Catalina de Ataide, la única mujer amada por Camoens, al decir de sus biógrafos oficiales.

Absuelto al fin, aun tuvo que padecer el cisne portugués nuevos reveses de fortuna. Acreedores implacables le hostigaron en forma bochornosa para ellos, más que para él. y no faltó uno muy poderoso,--el Gobernador Pedro Barreto-que le llevó consigo a Mozambique, para abandonarle luego a la mayor miseria, de la que vino a salvarle la liberalidad de algunos piadosos amigos suyos. que junto con recatar su persona, le restituyeron a la patria bien amada, pobre, enfermo y desengañado.

La publicación de su poema inmortal, en 1572, si acrecentó su fama, no 
mejoró la suerte de este hombre extraordinario: extraordinario por su genio, extraordinario por su vida aventurera, y extraordinario lambièn por sus desdichas. cualesquiera que hayan sido sus errores. Una mezquina pensión. pagada siempre con atraso. fué el único auxilio que obtuvo del poder real. y manos rapaces. quién sabe por qué causa y con qué propósitos, le hurtaron sus versos líricos. que con el titulo de Parnaso de Luis de Camoens, tenía ya dispuestos para imprimirlos.

Duranle diez años, desde su vuelta a la patria hasta su muerte, vegetó en la miseria, al extremo de que un esclavo javanés, llamado Antonio, que Camoens habia traido de la India, corria de noche las calles de Lisboa. pidiendo limosna para alimentar a su amo. El esclavo murió un dia, y entonces el desamparo del poefa no conoció límiles. Vivió de milagro. si asi pucde decirse, amargado todavia su corazón de hombre que amó a su patria sobre todas las cosas de la vida. por el torcedor de verla perder su antonomia, cuando los mismos encargados de velar por su independencia, favorecieron su incorporación a la corona de Castilla.

Sobrevinole al fin una grave enfermedad, que debía ser la última. y lué trasladado a un hospital, donde murió miserablemente en un día incierto de 1580. a los cincuenta y seis años de edad. Un fraile español escribió en un ejemplar de Os Lusiadas, que le perfenecía y que dejó en un convento de Guadalajara. la siguiente nota: Yo le ví morir en un hospital de Lisboa, sin tener una sábana con que cubrirse. después de haber triunfado en la India y de haber recorrido cinco mil quinientas leguas por mar. QQué aviso tan grande para los que de noche y de día se fatigan estudiando sin provecho, como la araña en urdir telas para cazar moscasl.

Esta fué, en sus rasgos generales y muy abreviada por cierto. porque la ocasión no consiente otra cosa. la vida de Luis de Camoens, según la refieren sus biógrafos más leídos. De su poema inmortal, si posible fuese. no quisiera yo hablar ahora, por no exponerme a repetir mal, ante un auditorio de personas cultas, lo que ofros han dicho bien y es sabido de todos. Empero. no es imporfuno transcribir, siquiera brevemente. las opiniones de algunos hombres de ciencia, poco conocidas tal vez. porque no están incorporadas a las historias literarias en uso. Para Alejandro de Humboldt. $O_{s}$ Lusiadas es el poema del mar.: para Edgardo Quinet, la epopeya del comercio, y también el poema de la alianza del Oriente con el Occidentes: para Esmerard. sla sintesis de los progresos de la navegación.: para Jorge Le Gentil corresponde ca un marco decisivo en la historia de la humanidad.: para Joaquin Nabuco es el poema de la colonización, de los acontecimientos remotos. y. por cosiguiente, el poema de la construcción del Nuevo Mundo. Además, el profesor Le Gentil resume en estos términos el carácter nacional y al mismo tiempo universal del poema: sa epopeya de Camoens. convencional en la apariencia. pero. en realidad, documental, está impregnada de espiritu moderno. Sólo se liga a la antigüedad por el respeto a los buenos modelos, y a la Edad Media, por el idealismo. trazo caracferística de la raza... Camoens comprendía la necesidad de juntar la nómina de 
las victorias a la de los descubrimientos: la necesidad de pasar de las causas a los efectos: de registrar las nuevas adquisiciones de la cartografia, de la hidrografia. de la botánica, de la medicina, de la etnología, y es por esto por lo que su poema, sin dejar de ser nacional, interesa a la evolución de la humanidad. AGUSTÍN DE CAMPOS, Sobre la incomprensión de Camoens por la crifica francesa): Al anotar. hace un momento. los principales sucesos de la vida de Camoens. cuidé de advertir que a eso se reducia, sobre poco más o menos, según el decir de sus biógrafos oficiales. Para ellos. Camoens es un gran poeta desgraciado, víctima inocente casi siempre de la envidia de los unos y de la maledicencia de los demás: un soldado valiente, un poco aventurero. otro poco camorrista en ocasiones, y un mucho enamorado, eso sí que no más que de doña Catalina de Ataide, ya lo sabemos.

Pero, me pregunto ahora, en esas biografías, que parecen escritas ad usum escolarum, ¿está completa, en lo que tiene de más intimo, la personalidad de Camoens? El soldado valiente y ardoroso ¿no fué sino la víctima resignada de las injusticias de los otros? El más alto prestigio intelectual de su raza. ¿movió únicamente su pluma para cantar las hazañas de los héroes y los afectos de su corazón? El poeta del amor. como se le ha llamado. ¿fué sólo el amante platónico y desesperanzado de la adolescéntula doña Catalina de Ataíde?

¡Nól Ni hay utilidad ninguna para su gloria en disfrazar la personalidad del hombre. Basta con meditar un instante en lo que dejan ver sus biógrafos y en lo que de sus obras se colige, para convencerse de que un espirilu inquieto como el suyo. no podia sentirse bien dentro de la disciplina a que se somete, por vocación, el soldado regular; que el cantor de las hazañas de Vasco de Gama, nunca olvidó sus rencores con la familia del héroe, que alcanzaban al héroe mismo. según está dicho en la penúltima estrofa del canto quinto de Os Lusiadas: que al comediógrafo del Aufo del rey Seleuco, aparentemente respetuoso del ideal dinástico. se le daba un ardife de la omnipotencia del monarca, como que con audacia inconcebible se atrevió a satirizar los amores de don Juan III con su real madrastra; y. finalmente. que el amante tímido y rendido. (asi, o poco menos, aparece en sus versos líricos) de la menina a quien vió por primera vez en una de las ventanas de palacio, amó. antes y después de conocerla, a otras muchas mujeres, y promovió escándalos y acuchilló rivales.

Hay un pequeño libro,-pequeño por su volumen. grande por la exquisita prosa portuguesa en que está escrito, - editado hace pocos meses en Lisboa, cuyo título es: O heroísmo, a elegancia, o amor. Su autor es Julio Dantas, a quien todos conocéis, cuando menos por La Cena de los Cardenales, que ahora mismo está representándose en Santiago. El libro de que os hablo colecciona las tres conferencias que Dantas pronunció el año pasado en Rio Janeiro. El título de la última es éste: Mulheres que Camoens amou. A esta conferencia he de referirme en mucha parte de lo que diga sobre el gran poeta portugués, al esbozar en forma muy somera, la personalidad del hombre, deficientemente estudiada por sus biógrafos en uno de sus aspectos más interesantes.

Se ha comparado a Camoens con el Petrarca, por el idealismo platónico de sus amores y por las formas líricas en que vertió sus pensamientos. Literariamente. 
nada hay que observar a esto. Petrarquista es Camoens por su manera poética, y platónico por la indole de los sentimientos que expresa. Pero. ¿es verdad que lo era? $\mathrm{Y}$ caso de serlo ideológicamente. que de otra manera no lo fué. cabe presentarle como el arquetipo de los enamorados platónicos?... Sus biógrafos. copiándose unos a otros, dicen que sí. Julio Dantas le llama gran soñador : lo cual. por cierto, no es indicio seguro de platonismo.

Veamos modo de orientarnos. Comencemos por considerar sus rasgos fisicos, que, si hemos de creer a la antropología, alguna importancia tienen en este caso.

Dice Julio Dantas, retratándole: .El torso musculoso y enorme,- torso de centauro-grande demás para el tamaño de las piernas; el cabello rubio: la barba rubia;... la nariz luerte, dilatada, corva en el perfil. globulosa y sensual en la punta, mezcla de las narices de Sócrates y de Cyrano: y. sobre todo, aquella expresión suya de sombrio orgullo, que el alto cuello plegado. levantándole la cabeza, tornaba más impertinente,... hacian del poeta una figura poco susceptible de inspirar, a primera vista, cualquier sentimiento amoroso. Coinciden algunos de estos rasgos. con los que apunta más brevemente Manuel Severin de Faria: -Fué Luis de Camoens, dice, de mediana estatura. Heno de rostro, algún tanto abulfado de frente, nariz larga, levantada en el medio y gruesa en la punta. cabello rubio. casi azalranado....

No hay duda que el tipo fisico de Camoens no armoniza con el del hombre en quien predominan los sentimientos espiritualistes sobre el ardor de los sentidos. Mejor se aviene con el del hiperestésico sexual, que el doctor Marañon describe asi, en un curioso estudio sobre la biología de Don Juan Tenorio. publicado recientemente: . En esta morfología hipergenital, dice el doctor Marañon, la talla es exigua $y$, sobre todo. desproporcionada, por un predominio muy poco elegante del tronco y cabeza sobre los miembros. La osamenta de la cara suele estar muy desarrollada: el mentón es frecuentemente prognático y. por fin. la barba y el bigote son recios y espesos..

Veamos ahora cómo amó Camoens.

Su primer amor fué su prima Isabel... Siempre nuestro primer amor es una prima, con la que nunca nos casamos.

La prima del poefa, hija del orgulloso Juan de Camoens, de la rama de Coímbra, era. según Dantas, suna linda muchacha de trece años, rubia, blanca. delicada, altiva como su padre, cuyos ojos verdes, de un verde transparente y luminoso de onda del mar, eran una de las maravillas de la vieja ciudad universifaria.. Se enamoraron recíprocamente, amores de nin̄os. pero transcurrieron cuafro. cinco años. y la orgullosa prima encontró poca cosa para ella, a un estudiante de diez y ocho. bravo y talentoso. pero feo y pobre.

¿Qué hizo entonces Camoens? Pues, fodas las locuras imaginables. desde decir a la hermosa niña que sparecia que fieras hircanas la hubiesen amamantado con su leche, y comparar sus ojos. sus admirables ojos, con los dimones verdes. . hasta rondar su casa impertinentemente como un espión. Por fin, averigua que su prima tiene otros amores; busca al que es objeto de ellos, un Don Alvaro Pinto. 
y el sauno rubio, el . Trinca Fortes, camo le llaman los estudiantes, arremete con su rival y con los hermanos de lsabel. en la plaza pública: siembra el terror y el desorden: la justicia interviene, y Camoens es obligado a salir de Coimbra. Por cierto que nada de esto aparece en la égloga segunda, en que el poeta, rendido amante, se queja bucólicamente de los desdenes de Belisa.

No debió de tardar mucho Camoens en consolarse de este malogrado amor. pues en poco tiempo le vemos enamorado sucesivamente de dos damas principales. dos admirables bellezas de esa época: la trigueña doña Violante, mujer del Conde de Linares. y la rubia doña Francisca de Aragón, a quien la reina amaba como hija. Ninguna de ellas tomó en serio estos amores, que, sin embargo, no dejarian de halagar su vanidad de mujeres, por la fama de que ya entonces el poeta disfrutaba. Doña Violante le alejó de su lado en forma muy gentil: recomendándole a los reyes, que le admitieron en Palacio. Luego que el poeta. dice Julio Dantas, comenzó a frecuentar el dorado gineseo, que era la cámara de la reina doña Catalina, hizose, en torno suyo. un movimiento de curiosidad y de interés. Todas las damas le rodeaban. Todas le daban motes para que les hiciese versos. Todas quedaban en éxtasis, encantadas, al oír a la sirena del Palacio..

Ahí conoció a doña Francisca de Aragón. notable entre todas por el desdên altivo con que repelió siempre los requiebros de sus apasionados. No gastó igual rigor con Camoen3, según parece, porque la lisonjeaba verse cortejada por un tan gran poeta: pero. en suma. ¿qué favores obtuvo de ella el cisne porlugués? Nada más que las mismas sonrisas con que le había acogido la condesa de Linares. ¡Nada más!

A consolarle de estas empresas malogradas, vino el casual encuentro con la mujer que fué el más grande amor de su vida. He nombrado a doña Catalina de Alaide.

Era entones una niña. Su belleza delicada deslumbró al poefa. que pensó. al verla,-êl mismo lo ha dicho,- - en la aparición de Laura al Petrarca. El genio de Camoens. - no su figura lisica, probablemente-impresionó también a Catalina. Ambos se amaron; esto parece indudable, y durante un año vivieron en dichoso idilio. Pero no tardó la envidia de sus émulos en tomar pie de algunas infantiles locuras del fogoso enamorado, para indisponerle con la familia de Catalina y la madre de esta joven, doña María Bocanegra, dama de la reina, se quejó de que el poeta le requebraba a su hija: por lo que le fué negada a Camoens la entrada a Palacio. El efauno rubio. como le denomina Dantas, cometió las mayores imprudencias por tornar a ver a su amada, pero no lo consiguió. Furioso. despechado entonces, juró vengarse de todos, sin exceptuar a los propios reyes, y escribió e hizo representar aquel inaudito Aufo del rey Seleuco. de que hablé antes. Amenazado, perseguido muy justamente, por cierto, huye de la Corte. vive algún tiempo oculto en Ribatejo, $y$ al fin se embarca para Africa. Ya no volvió a ver a la rubia menina, que años después, siempre fiel a la memoria de ese amor, resbaló dulcemente en la tumba. Su muerte, de la que tuvo tardia noticia, inspiró al gran poeta el más bello soneto de la lengua porfuguesa.

Pero aun vivia doña Calalina cuando Camoens regresó de Africa a Lisboa. 
con la intención de embarcarse para la India. No intentó verla, según parece. acaso porque ya su rostro estaba desfigurado por la herida que le vació el ojo derecho. Por el contrario. apresuró su embarco, pero naulragó a poco de salirno creo que ningún hombre haya naufragado tantas veces -y se vió forzado a regresar a Lisboa. Entonces conoció a la infanta doña María. una de las mujeres más hermosas y sabias de su tiempo. que hablaba el griego y el latín como los ciudadanos de Atenas y de Roma en los siglos de Pericles y de Augusto.

Aunque sin correspondencia, es verdad. y con el ardor que él ponia en estas empresas, enamoróse de ella desatinadamente Camoens, y tales locuras dijo y de tan insólitas temeridades se hizo reo, que el palacio de Santa Clara se cerró súbitamente para él. como primer aviso, y dias más tarde fué obligado a huir. por haber caido en un lazo que hábilmente se le tendió: la riña con Gonzalo Borges en la procesión de Corpus.

Ya se ve que el amor a doña Catalina, viva aún, no impedia a Camoens enamorarse de otras mujeres. No faltará quien piense que estos amores eran platónicos. porque quedaron rezagados en el camino y la posesión no los sazonó. Si pudiéramos evocar la iracunda sombra del poeta, acaso ella nos diría que no fué suya la culpa.

Embárcase al fin para la India el soldado aventurero, y ahí disfruta, como de paso, del amor exótico de mujeres de rostros bronceados. Una llega a interesarle: Bárbara, que le inspira dulcísimas endechas. Pero esto es apenas un capricho o. mejor, un desahogo de su ardiente naturaleza. Una mujer de su raza le apasiona luego: es una espiritual cortesana que tiene por nombre Gracia. Con ella derrocha los dineros que allegó en su expedición a las Molucas, y en medio de las saturnales de Goa es donde recibe la noticia de la muerte de doña Catalina de Ataide, a quien él habia ofendido en sus versos. por sospecharla infiel.

¡Catalina de Ataide, la más grande pasión de su vida! El recuerdo de sus ojos azules iquién lo dirial aun sirve a Camoens de incentivo para un nuevo amor. Ahora es una española: aquella srubia Dinamene de los ojos garzos?: sla cordera gentil.,--son también palabras suyas, -que èl ama por parecerse a Catalina, y que murió al lado suyo en un postrer naufragio.

¿Fué ésta la úlfima mujer a quien amó el poeta? ¡Quién sabel En sus versos hay los nombres de otras, de épocas distintas de su vida: Beatriz. Leonor, Juana. Dominga, Ana, Inés. Grande, desmedido en todo, no podía sino serlo tambièn en el amor. Tenía la tara erótica de la familia: uno de los Camoens del Algarve se habia robado una monja de Odivelas, y otro Camoens, de Coimbra, asaltó. por causa de una mujer. el monasterio de religiosas de Santa Ana. La terrible ley de la herencia alivia, en cierto modo, a Luis de Camoens de la responsabilidad de sus excesos.

Pero, aquí surge otra vez la interrogación que antes me hice: esta hiperestesia sexual del fauno rubio, ¿conviene a un devoto del amor platónico? ¿Lo era Camoens?.

En sus versos, si; no, seguramente, en su vida.

¿Implica esto una contradicción entre el hombre y el poeta? 
Sí, hasta cierto punto, pero no inconciliable ni peregrina, porque la historia de la literatura ofrece muchos casos análogos, que denuncian, en algunos escritores, verdaderos desdoblamientos de la personalidad. En la vida vulgar misma. estas dualidades ingenuas no son raras. Por otra parle. queda por averiguar qué sirve mejor para apreciar la individualidad de un hombre: las ideas que expresa o los actos que ejecuta. Las primeras, si son constantes. hay motivo para creerlas sinceras y concebidas en una completa libertad de espiritu; los segundos estan subordinados muchas veces a la fuerza mayor de agentes externos, que desvian su camino o provocan reacciones imprevistas. Como quiera que sea. no es posible. en último análisis, aplicar al genio el mismo rasero que al burgués.

Camoens continúa siendo la más alta figura intelectual de la literatura portuguesa. que toma en êl su verdadero principio. Grandes escritores la han honrado: en lo antiguo, como precursores de Camoens, Sá de Miranda, Bernardino Riveiro. Gil Vicente, caro también a las letras españolas; en lo moderno, para no citar sino a los principales, que me son más conocidos, Almeida Garret.. Alejandro Herculano, Antonio Feliciano del Castillo. Camilo Castello Branco, Anthero de Quental, Eca de Queiros, el insigne Oliveira Martins, Teófilo Braga, Guerra Junqueiro. Eugenio de Castro, Julio Dantas y otros muchos que ahora oigo aplaudir. pero que yo no he tenido ocasión de leer.

La celebración del cuarto centenario del nacimiento de Luis de Camoens, honra a la colonia portuguesa que vive entre nosotros. La honra como patriota y como comprensiva de los valores intelectuales de su raza: lo que, en la época que alcanzamos, no viene a ser una misma cosa. Hoy, el entusiasmo de los más no lo despierta el silencioso laborador de las obras del espíritu, y menos aún si ya está del otro lado de la vida. Ahora el músculo vence al cerebro. Esparta triunfa sobre Atenas. Por eso es, señores, por que la iniciativa de la colonia portuguesa de Santiago, para recordar en esta fecha al más grande de sus poetas. merece el aplauso de todos, y muy especialmente el de los que aun no nos damos por notificados del aviso de aquel buen fraile español a los que -se fatigan estudiando sin provecho. como la araña en urdir telas para cazar moscas. 